\title{
HIVIAIDS in Kisii County: Current Status and Challenges
}

\author{
Gladys Nyamoita Mokua ${ }^{1, ~}$, Geoffrey Mokua Maroko², Augustus Onchari Nyakundi ${ }^{3}$, \\ Meshack Ondora Onyambu ${ }^{1}$ \\ ${ }^{1}$ Department of Pharmacognosy and Pharmaceutical Chemistry, Kenyatta University, Nairobi, Kenya \\ ${ }^{2}$ Department of Languages and Linguistics, Machakos University, Machakos, Kenya \\ ${ }^{3}$ Department of Communication, Chuka University, Chuka, Kenya
}

\section{Email address:}

mokuag@yahoo.com (G. N. Mokua),mokua.gladys@ku.ac.ke(G. N. Mokua),gmaroko@mksu.ac.ke(G. M. Maroko), augustusosoro@gmail.com (A. O. Nyakundi), mesh102002@yahoo.com (M. O. Onyambu)

${ }^{*}$ Corresponding author

\section{To cite this article:}

Gladys Nyamoita Mokua, Geoffrey Mokua Maroko, Augustus Onchari Nyakundi, Meshack Ondora Onyambu. HIV/AIDS in Kisii County: Current Status and Challenges. International Journal of HIV/AIDS Prevention, Education and Behavioural Science.

Vol. 5, No. 2, 2019, pp. 147-155. doi: 10.11648/j.ijhpebs.20190502.20

Received: November 22, 2019; Accepted: December 9, 2019; Published: December 20, 2019

\begin{abstract}
In 2012, adult HIV/AIDS prevalence in Kisii County was disproportionately high at 8.6\%, against the national average of $5.6 \%$. Thus, the researchers set out to investigate the current status and intervention measures in place in combating the condition. Mixed method approach combining both qualitative and quantitative data collection techniques was used. It entailed a desk review of HIV/AIDS materials for the period 2010-2018. Published data on HIV/AIDS in Kisii County from a diverse set of stakeholders was used. Quantitative data was also extracted from online databases, County reports and proposals. Qualitative data was generated from key informant interviews and focus group discussions. Comparative analysis of the qualitative information obtained from the respondents and the documented information was done and conclusions were drawn. Quantitative data was expressed as percentages and the data was presented in form of graphs and tables. Findings indicated that although HIV and AIDS remain a challenge in Kisii County, commendable strides have been made in its management and possible containment. The Kenya HIV estimates report for 2018 indicates that Kisii County has a prevalence rate of $4.4 \%$ against the national prevalence of $4.8 \%$. The study also revealed that over $80 \%$ of HIV response is funded from external sources with more focus on biomedical interventions with less priority on the non-biomedical interventions. Based on the findings, the study recommends coordination among implementing partners for accurate data documentation and resource distribution. Deliberate efforts also need to be made to increase resources for prevention especially behavioral and structural interventions.
\end{abstract}

Keywords: Behavioral, Biomedical, County, Interventions, Kisii, Prevalence

\section{Introduction}

Kenya has forty seven (47) counties with Kisii County being one of them. Its neighboring counties are Nyamira to the North East, Narok to the South, Homabay and Migori to the West. It lies between latitude $30^{\circ}$ and $10^{\circ} \mathrm{S}$ and longitude $35^{\circ} 38^{\prime}$ and $35^{\circ}$ East. The County covers a total area of $1317.5 \mathrm{~km}^{2}$. It is divided into nine (9) Sub-Counties namely Bobasi, Bomachoge Borabu, Bonchari, South Mugirango, Kitutu Chache North, Kitutu Chache South, Nyaribari Masaba,
Nyaribari Chache and Bomachoge Chache (Figure 1).

The estimated population in the County by 2018 was $\approx 1,406,043$ comprising of 674,901 males $(48 \%)$ and 731142 females (52\%) [1]. Youths aged 15-24 years constitute $21 \%$ of the population while children below 15 years constitute $42.3 \%$ of the population [2]. Bobasi Sub-County has the highest population while Bomachoge Chache Sub-County has the least population (Table 1). With the population growth rate of $2.2 \%$ per annum, it is estimated that by the year 2022, the total population will be $\approx 1533977$ [1]. 


\section{County Health Facility Distribution by Type COUNTY OF KISII}

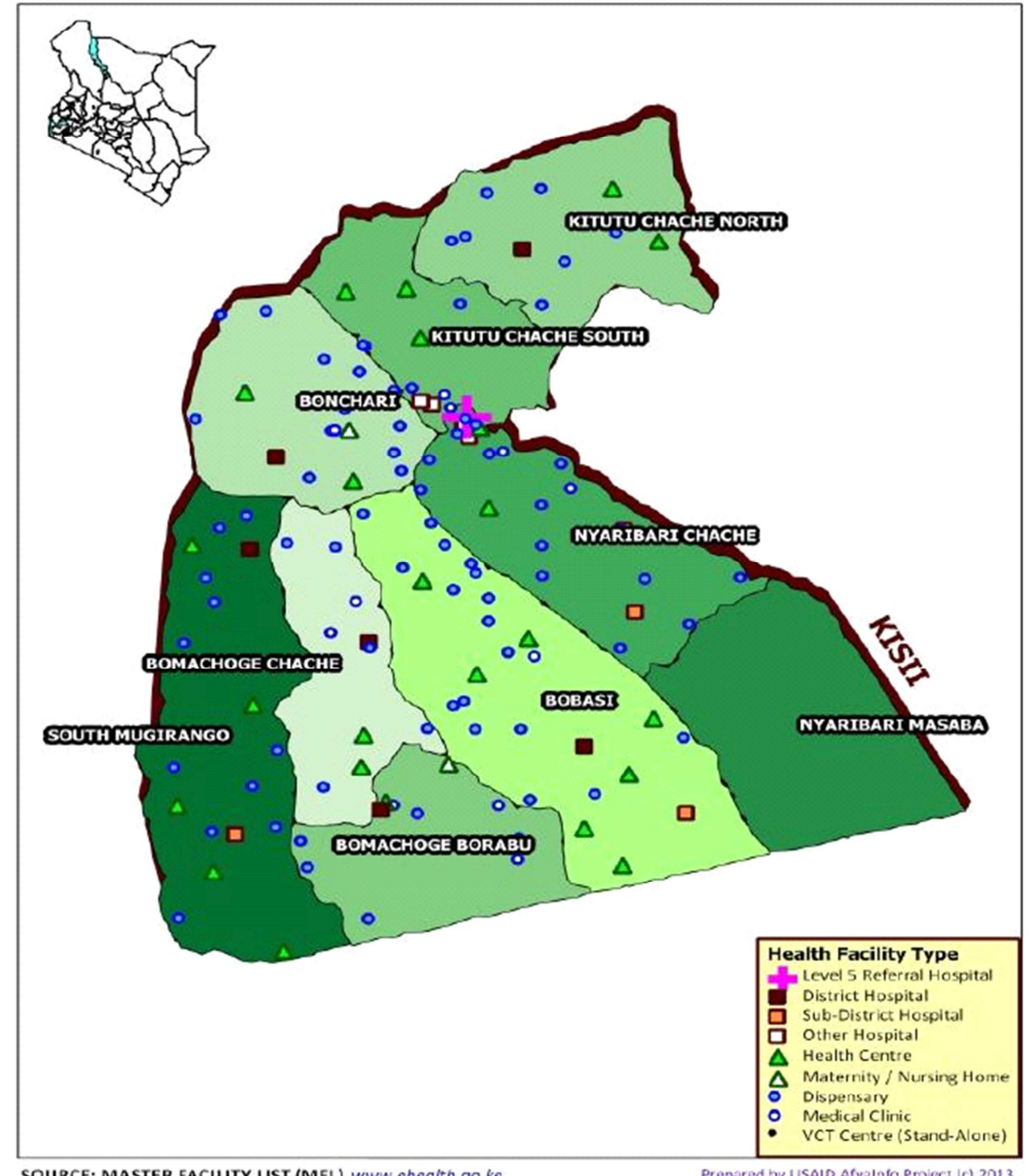

Figure 1. Kisii County Map Showing the Nine (9) Sub-Counties.

Table 1. Catchment Populations.

\begin{tabular}{lll}
\hline S/No. & Sub-County & Population Projections 2018 \\
\hline 1 & Bobasi & 231933 \\
2 & South Mugirango & 194076 \\
3 & Kitutu Chache South & 161229 \\
4 & Nyaribari Chache & 158318 \\
5 & Nyaribari Masaba & 148954 \\
6 & Bonchari & 139857 \\
7 & Bomachoge Borabu & 130806 \\
8 & Kitutu Chache North & 126743 \\
9 & Bomachoge Chache & 114127 \\
& TOTAL & 1406043 \\
\hline
\end{tabular}

Source: Kisii County Work plan 2018

According to the United Nations Joint Program on HIV/AIDS, 36.7 million adults and children are living with HIV/AIDS worldwide. Of these, 1.6 million are estimated to be in Kenya with Kisii County accounting for $2.2 \%$ [3]. It is estimated that in 2012, the HIV/AIDs adults' prevalence in Kisii County was $8.9 \%$ which was way above the national average of $5.6 \%$ The HIV prevalence among women in the County was higher $(8.5 \%)$ against the national average of $7.6 \%$ and that of men $(7.3 \%)$, was also relatively high compared to the national average of $5.6 \%$ [4]. The female gender is apparently more susceptible to HIV and AIDS than their male counterparts in the County.

According to the Kisii County Annual Workplan for 2018, infections from HIV (11.7\%) and lower respiratory (8.4\%) are the leading causes of deaths in the County. This is followed by prematurity and low birth weight (6.3\%), tuberculosis (TB) (6.1\%) and birth asphyxia and trauma (5.8\%). In the Kenya demographic Health Survey of 2014, Kisii County ranked fifth $(8 \%)$ among the most affected Counties with HIV after Homabay (25.7\%), Siaya (23.7\%, Kisumu (19.3\%) and Migori (14.7) in that order [5]. 
By the end of 2015 [6], about 34,014 people were living with HIV in the County with $22 \%$ aged $15-24$ years and $6 \%$ being children under the age of 15 years. According to the report, the HIV prevalence rate in 2015 had reduced to $4.7 \%$ with a higher prevalence rate of $5.0 \%$ in women than in men at $4.3 \%$. The annual new infection was estimated to be 5,976 people (4 891 adults and 1085 children). Deaths due to AIDS-related conditions in 2015 were about 594 adults and 118 children.

According to the Kenya HIV estimates for 2017 report, the National adult HIV prevalence rate is estimated at $4.9 \%$ with prevalence higher among women $(5.2 \%)$ than men $(4.5 \%)$. In descending order, Counties with the highest adult HIV prevalence in 2017 are presented in (Table 2) [7].

Table 2. Counties with the Highest Adult HIV Prevalence.

\begin{tabular}{lll}
\hline S/No. & County & Prevalence (\%) \\
\hline 1 & Siaya & 21.0 \\
2 & Homa Bay & 20.7 \\
3 & Kisumu & 16.3 \\
4 & Migori & 13.3 \\
5 & Busia & 7.7 \\
6 & Nairobi & 6.1 \\
7 & Vihiga & 5.4 \\
8 & Kitui & 4.5 \\
9 & Kakamega & 4.5 \\
10 & Kisii & 4.4 \\
11 & Tans Nzoia & 4.3 \\
12 & Muranga & 4.2 \\
13 & Nyamira & 4.2 \\
14 & Makueni & 4.2 \\
15 & Mombasa & 4.1 \\
16 & Taita Taveta & 4.1 \\
17 & Kiambu & 4.0 \\
\hline
\end{tabular}

Source: Kenya HIV Estimates, 2018.

These new estimates confirm a decline in HIV prevalence among both men and women at both national and county levels. Of interest, Kisii County has registered a commendable decline from $8.0 \%$ in 2014 [5] to $4.4 \%$ in the 2017 [7].

In the fight against the HIV/AIDS epidemic, the County in partnership with other stakeholders has implemented a number of interventions which include stigma reduction campaigns, risk reduction, counseling and skills building, male and female condom demonstration and distribution. Others include mother-to-child transmission prevention campaigns, free testing and counseling and free administration of antiretroviral drugs. Prompted by a disproportionately high HIV/AIDS prevalence in Kisii County in 2012 at $8.0 \%$ [5], the researchers set out to investigate the current status and intervention measures in place in combating the diseases.

\section{Materials and Methods}

The study was undertaken as part of a research project entitled: "A Situational Analysis of Intervention Measures in the Management of HIV/AIDS Prevalence in Kisii County".
The research adopted a mixed methods approach on the assumption that collecting diverse types of data best provides an understanding of a research problem [8]. The study began with a broad survey of Kisii County- specific HIV/AIDS desk review of literature for the period 2010-2018 to uncover the status and challenges. The review entailed making inferences and interpreting HIV/AIDS information from a diverse set of stakeholders including the Government of Kenya (GoK), the National AIDS Control Council (NACC), the National AIDS and STI Control Program (NASCOP), and Kisii County.

The purposively selected documents for analysis were the Kenya Demographic \& Health Survey [1], Kisii County HIV/AIDS Strategic and Implementation Plan 2014/152018/19 (KCHASIP) [2], UNAIDS DATA [3], Kenya Aids Response Progress Report [4], Kenya HIV Prevention Revolution Roadmap [5], Kenya HIV Estimates 2015 [6] and the End-Term Review Report for Kisii County Health Sector Strategic and Investment Plan 2013-2018 (KCHSSIP). Online databases provided quantitative data on the status of HIV/AIDS in Kisii County. These were the District Health Information System (DHIS) and HIV Implementing Partners Online Reporting System (HIPORS) [9].

Criteria for inclusion of documents for desk review and online data in this study were pegged on their suitability to provide data on status and challenges on HIV/AIDS management in the County. Detailed qualitative, open-ended interviews to collect views on the status of HIV/AIDS in the County from key informants were carried out. Thus, key informant interviews involving six (6) out of the nine (9) Constituency AIDS Control Coordinators (CACCs) and all the five (5) Sub-County HIV/AIDS coordinators were carried out. Further, a key informant at the Gender Based Violence unit at the Kisii Teaching and Referral Hospital was also interviewed. The interviews focused on the HIV/AIDS prevalence and control activities in their areas of assignment, including issues on Gender Based Violence (GBV).

For inter-rater reliability, plenary sessions were held to compare and collate information gathered from the written documents and from the online sources. Any disagreements were discussed till consensus was reached. Comparative analysis of the qualitative and quantitative information was done and conclusions drawn. Findings were organized and discussed according to two themes: Epidemiological dynamics \& geographical distribution; and strategies for reducing HIV/AIDS in Kisii County. Quantitative data was expressed as percentages and the data was presented in form of graphs and tables.

To anchor the research process within acceptable ethical standards, clearance was given by Chuka University Institutional Ethics Review Committee under approval Number CU/IERC/NCST/1853. Further, Research Permit Number NACOSTI/P/18/50245/24190 was granted by the National Commission for Science, Technology and Innovation (NACOSTI). Where human subjects were involved, informed consent was sought. In addition, respondents were assured of confidentiality and anonymity. 


\section{Findings}

\subsection{Epidemiological Dynamics and Geographical Distribution}

The HIV epidemic in the County exhibits some gender and geographical disparities. There are variations in HIV burden with the epidemic concentrated among key populations despite their small population. According to the Kisii County HIV \& AIDs Strategic Plan 2014/15-2018/19 report [2], although this population represents less than $2.7 \%$ of the general population, it contributes a third ( $1 / 3)$ of all new HIV infections. Epidemiological dynamics with respect to modes of transmission, sex and age, indicate that girls, women, and key populations such as sex workers, people who inject drugs (PWID), men who have sex with men (MSM) and people in prison are disproportionately affected with HIV. From the key informant interview, one Constituency AIDS Control Coordinator (CACC) noted that:

"The number of men who have sex with men is on the rise in Kisii County. Unfortunately, those involved include married men and they wish not to be identified".

Key drivers of HIV and AIDS in the County are identified as sex workers who include female, male and trans-gender and their clients; casual heterosexual sex; involvement of some HIV sexual risk practices which are socio-cultural such as "house entering" where widows exchange sexual partners willingly though not universally accepted. This socio-cultural practice was reported by another CACC who said that:

"Widows present themselves in the antenatal clinics when the community is aware that they do not have husbands".

Others include sugarcane cutters, soapstone carvers, banana and sugarcane sellers, adolescents and young women. Another CACC reported that:

"Hair dressers are a dangerous group in spreading HIV/AIDs in the County".

According to the Kisii County End-Term Review Report for the Kisii HIV Strategic Plan for 2014/2015-2018/2019 in 2017, there are marked gender disparities which characterize the HIV epidemic with higher prevalence amongst women at $5 \%$ compared to men at $4.3 \%$. There is also a treatment gap of over $20.2 \%$ adults and children in need of antiretroviral therapy (ART) but not currently receiving treatment. Antiretroviral therapy (ART) coverage is $77 \%$ in eligible women compared to $80 \%$ in men. The epidemic is also geographically diverse ranging from a high prevalence among communities living along the administrative borderline. This could be associated with cross-infection at the border regions. Accordingly, health facilities like Mosocho and Nyabiosi Dispensaries; Raganga and Matongo Health Centers have recorded a high HIV testing and counseling services (HTS) at $6 \%$. Other regions observed with high prevalence include sugarcane growing and soapstone areas in South Mugirango Sub County.

The estimated number of PLHIV per sub-County is presented in Table (3).
Table 3. Granulation of HIV per sub-County in Kisii County.

\begin{tabular}{lllll}
\hline S/No. & Sub-County & $\begin{array}{l}\text { Population } \\
\mathbf{2 0 1 5}\end{array}$ & $\begin{array}{l}\text { Estimated no. } \\
\text { of PLHIV }\end{array}$ & \% \\
\hline 1 & Bobasi & 215320 & 7909 & 3.67 \\
2 & South Mugirango & 191193 & 7023 & 3.67 \\
3 & Kitutu Chache South & 164791 & 6053 & 3.67 \\
4 & Nyaribari Chache & 147167 & 5406 & 3.67 \\
5 & Nyaribari Masaba & 140013 & 5143 & 3.67 \\
6 & Bochari & 130006 & 4775 & 3.67 \\
7 & Bomachoge Borabu & 126148 & 4911 & 3.89 \\
8 & Kitutu Chache North & 122674 & 4506 & 3.67 \\
9 & Bomachoge Chache & 110063 & 4043 & 3.67 \\
& TOTAL & 1347375 & 49769 & 3.69 \\
\hline
\end{tabular}

Source: Kisii County HIV \& AIDs Strategic Plan 2014/15-2018/19.

\subsection{Strategies for Reducing HIV/AIDS in Kisii County}

Majority of the interventions in the county are biomedical with few behavioral and structural interventions. The following are the strategies used in the county in the fight against HIV/AIDS:

\subsubsection{Biomedical Interventions}

(i) HIV Counseling and Testing Coverage

The KDHS (2016) report indicates that $35 \%$ of men and $19 \%$ of women in Kisii County had never tested for HIV [10, 11]. This revealed a disparity between women and men who have never tested for HIV status. A Sub-County HIV/AIDS Coordinator said that:

"Men use their wives' HIV test results. Men say if their wives have been tested, they have also been tested. When asked to accompany their wives to ANC clinics, they ask their wives whether they are the ones who are pregnant".

To address this disparity, there is need for concerted effort to increase testing rates among men in the County. There are sero-discordant couples in the County (when one partner is HIV negative and the other is positive) and when such couples are unaware of their status, they greatly contribute to new infections. The County therefore needs more innovative strategies to improve on HIV testing and counseling to bridge the unmet gaps. Trends in HIV testing and counseling in Kisii County are presented in (Figure 2). Massive testing was carried out in 2016 where 6520 people tested positive.

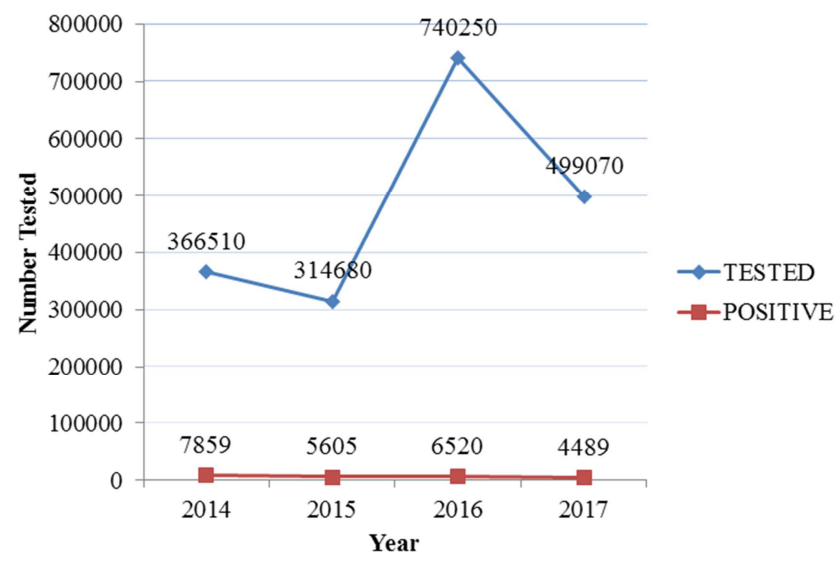

Figure 2. Trends in HIV Testing and Counseling in Kisii County. 
(ii) Expanding Access to HIV Treatment

In Kisii County, 34,382 adults and 6,068 children were in need of ART in 2013. Adult ART coverage was at $40 \%$ $(13,629)$ while pediatric ART coverage was at $19 \%$ (1 169). This was much lower than the national coverage of $81 \%$ and $38 \%$ for adults and pediatrics respectively. The county was ranked 42 and 43 out of 47 in ART coverage among adults and children respectively. It was estimated that 1,352 adults and 492 children died of AIDS related conditions in 2013. However, these mortalities reduced to 594 and 118 in 2015 for adults and pediatrics respectively [11].

Following the review of HIV treatment guidelines and adoption of the UNAIDS "90:90:90" approach to measuring achievement in HIV service delivery, in 2013/2014 financial year (FY), the number of clients started on ARVs increased to $82.4 \%$ (denominator being people on care). Since then, there has been a steady increase in the percentage of eligible HIV clients on ARVs. In 2014/15, the percentage increased progressively from $90.7 \%$ (22 055) to $92.1 \%$ in $2015 / 16$ $(25,755)$ and then to $99.9 \%$ (27 522) in $2016 / 17$ FY. In the 2017/18 FY, the County targeted 34,014 HIV positive clients to access ART with a projection of $28912 \mathrm{HIV}$ clients in 2018/19 FY.

A report by the Kisii County on the HIV Implementing Partners Online Reporting system (HIPORS) indicates ART coverage for the financial year $2016 / 2017$ as $63 \%$ each for adult, pediatric [9]. The percentage coverage reported by the HIPORS differs from the percentage coverage revealed by the study. This could be attributed to the low reporting rate by the registered implementing partners on the HIPORS in the 2016/2017 financial year.

On overall the research observed progressive ART coverage achievements over time. This may be attributed to robust programming for key population, outreaches and strong linkage mechanisms. However, it is important to note that even with these achievements, stigma and discrimination has made disclosure a challenge. This was confirmed by a Sub-County HIV/AIDS Coordinator who said that:

"Mostly, women are not able to disclose their HIV status to their spouses for fear that they can be divorced by their husbands or discriminated by the society".

(iii) Elimination of Mother-to-Child transmission

As a step towards achieving HIV epidemic control, Elimination of Mother-to-Child Transmission (eMTCT) plays a critical role in preventing new infections. HIV is most often transmitted from mother-to-child during pregnancy, delivery and breastfeeding. Breastfeeding is crucial for a child's survival, growth and development. Providing antiretroviral medicine to mothers throughout breastfeeding period is critical for significant reduction of mother-to-child transmission.

The county's needs analysis indicates that there are 4118 HIV-positive mothers in need of ARVs. The number of HIV infected expectant mothers on Highly Active Retroviral Therapy (HAART) increased steadily in 2013/2014 and 2014/15 followed by a decline in 2015/16 and 2016/17. However, there was an increase in $2017 / 2018$ FY to 1520
(62\%). The widest gap was in 2016/17 FY where the target for HAART was 2301 but only 1209 positive expectant mothers received the treatment (Figure 3). The County therefore has a $38 \%$ gap to be met in order to achieve reduction of eMTCT rates. Nevertheless, the current County eMTCT rates are at $8 \%$ which is way above the national target of 5\% and twice the regional rate of $4 \%{ }^{[3]}$. In $2015,15 \%$ children were reported to be infected with HIV which indicated a decline from $44 \%$ in 2013. This was a noticeable progress in reducing mother to child transmission. The observed significant results could be attributed to the increased investments by the county on HIV prevention and reduction, Beyond Zero campaigns, introduction of Option B+ through Bring Back the Mothers campaign and free maternity.

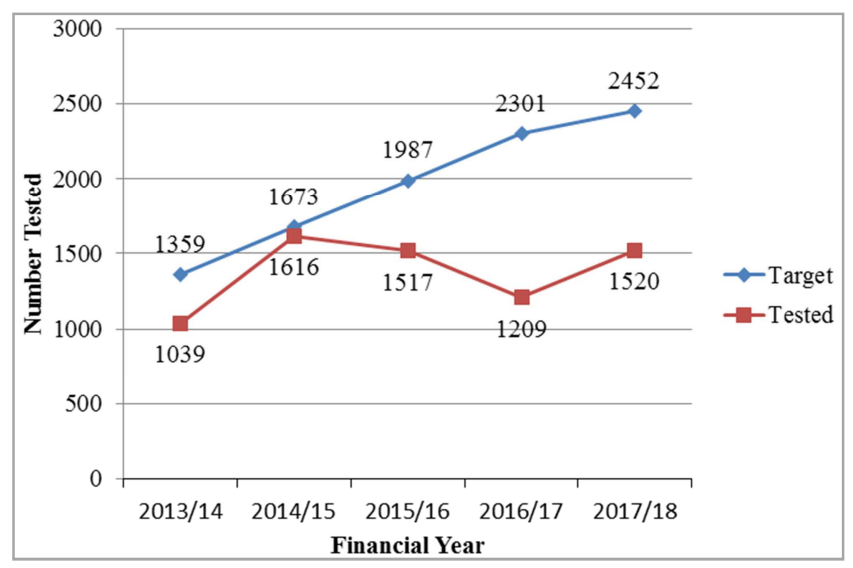

Figure 3. Trends in HIV Positive Mothers Receiving HAART in Kisii County.

The $38 \%$ gap could be attributed to some mothers declining to take up eMTCT services mainly due to stigma and lack of commitment from some health care providers in the provision of the comprehensive HIV care services. The unmet gap could also be attributed partly to the health workers industrial action that interrupted service delivery for five months in all public health facilities (www.thelancet.com). Low levels of disclosure among partners, knowledge gap and staff attitude towards the PLHIV could be reasons.

To further increase eMTCT rates, strategies like universal attendance of antenatal clinic (ANC) by pregnant women, increased male involvement, and increased knowledge about prevention of Mother to Child Transmission (PMTCT) universal testing of pregnant women for HIV and provision of ARVs to reduce the risk of HIV transmission could be used. Male involvement is a key strategy in increasing eMTCT rates. However, currently there is no documentation showing male involvement and even at the national level their involvement is very limited at $4.5 \%$ [4]. This was emphasized by a CACC who observed that:

"Men are difficult and unsupportive on the fight against HIV/AIDs".

(iv) Voluntary Medical Male Circumcision (VMMC)

According to the KDHS (2014) report [10], 98\% of the men aged 15-49 years who participated in the study reported having been circumcised. Though Kisii County is a 
traditionally circumcising community, the practice should be carried out in safe and hygienic conditions. Efforts should target the remaining $2 \%$ in order to achieve $100 \%$ compliance. The study also observed that there are a number of non-locals in the County and therefore there is a need to develop programs to sensitize this group of people. In addition, male circumcision should be encouraged before sexual debut.

\section{(v) Condom Use}

About $89.8 \%$ of the men and $81.7 \%$ of the women in the County believe that condom use can prevent HIV transmission. However, $48 \%$ of men who had reported to have two or more sexual partners did not use condom during their last sexual intercourse [11]. Youths say they use condoms the first time they have a sexual encounter with their partners. On subsequent occasions, they engage in condomless sex. Discordant couples do not like using the condom. A Sub-County HIV/AIDS Control Coordinator narrated as follows:

"A 20 year old girl living with HIV visited her boyfriend armed with condoms. Later at night, she asked the boyfriend to use a condom given that she was living with $H I V$. The boyfriend refused despite her persistent plea that he uses a condom. They engaged in unprotected sex. She was later married to someone else with whom they now have two children. The two partners have not been reached for testing".

Having multiple sexual partners puts one at a high risk of HIV infection especially if they are not using condom consistently and safely. It is alleged that in some instances the low uptake of condoms in Kisii County is due to the erratic supply of condoms in the County. There is therefore need to supply HIV and STI related commodities to the County to promote effective use of condoms to effectively reduce the risk of HIV infections in the County.

\subsubsection{Behavioral Change Interventions}

(i) HIV Education and Awareness in Kisii County
Accurate and adequate information concerning HIV and AIDS prevention is necessary for a person to make informed choices on sexual behavior. In the 2014 KDHS report [11], $80 \%$ men and $71 \%$ women demonstrated comprehensive knowledge of HIV and AIDS. The HIV education and awareness are important components in HIV prevention. The education was integrated into the school curriculum in Kenya through the Education Sector Policy on HIV and AIDS, 2004. The policy includes education about HIV prevention, care and support for school pupils and education personnel. However, the issue became controversial and was received with mixed reactions. The concerns include the unique needs of learners living with HIV and AIDS and the need for age appropriate comprehensive sex education to enable learners make informed decisions [12]. The 2004 policy has since then been revised and led to the Education Sector Policy on HIV and AIDS, 2013 [13]. The 2013 policy provides a framework for prevention, treatment, care and support as well as the management of response within the education sector at all levels. The policy also proposes a strengthened coordination mechanism to improve implementation of HIV and AIDS programs by various stakeholders.

The "Kenya Fast Track Plan to End HIV and AIDS among adolescents and young people, 2015" estimates that 13079 adolescents aged 15-24 years are living with the virus with 5 012 not knowing their HIV status [14]. This could be contributing to the new infections in this age group.

The study findings observed a general decline in HIV positivity rate from 2.3 in 2014 to 0.8 in 2018 the County (Table 4). This indicates increased awareness in the County. However, the County needs to use mass media (radio and TVs programs and print media), sporting activities and also intensify campaigns to raise awareness about HIV especially among adolescents and young adults. The county also needs to explore the need for communicating HIV messages using braille for the visually impaired, sign language and pictorial for those with hearing impairment.

Table 4. HIV Tested and positive per age group.

\begin{tabular}{llllllll}
\hline \multicolumn{2}{l}{ Tested } & Positive per age group & & & \\
\hline \multirow{2}{*}{ Period } & \multirow{2}{*}{ Total Tested HIV } & $\begin{array}{l}\text { Female 15-24yrs } \\
\text { Receiving HIV } \\
\text { + Results }\end{array}$ & $\begin{array}{l}\text { Female above } \\
\text { 25yrs Receiving } \\
\text { HIV + Results }\end{array}$ & $\begin{array}{l}\text { Female under } \\
\text { 15yrs Receiving } \\
\text { HIV + Results }\end{array}$ & $\begin{array}{l}\text { Male 15-24yrs } \\
\text { Receiving HIV } \\
\text { + Results }\end{array}$ & $\begin{array}{l}\text { Male above } \\
\text { 25yrs Receiving } \\
\text { HIV + Results }\end{array}$ & $\begin{array}{l}\text { Male under } \\
\text { 15yrs Receiving } \\
\text { HIV + Results }\end{array}$ \\
\hline 2014 & 366510 & 1393 & 3080 & 398 & 756 & 1885 & 347 \\
2015 & 314680 & 1016 & 2407 & 287 & 192 & 1399 & 304 \\
2016 & 740258 & 1081 & 2955 & 223 & 274 & 1767 & 220 \\
2017 & 499070 & 793 & 1965 & 143 & 202 & 1266 & 120 \\
2018 & 753858 & 1095 & 2859 & 196 & 268 & 1812 & 165 \\
\hline
\end{tabular}

Table 4. Continued.

\begin{tabular}{llllll}
\hline Period & Total positive & Total positive & Total Enrolled in Care & \% linked to care & Positivity Rate \\
\hline 2014 & 7859 & 7859 & 5676 & 76.7 & 2.3 \\
2015 & 5605 & 5605 & 5496 & 103.5 & 1.7 \\
2016 & 6520 & 6520 & 6144 & 100.3 & 0.8 \\
2017 & 4489 & 4489 & 4470 & 103.7 & 0.9 \\
2018 & 6395 & 6395 & 6300 & 102.1 & 0.8 \\
\hline
\end{tabular}

Source: DHIS 2018 
(ii) Sex before the age of 15 years

Delay in sex debut is a key strategy for reducing the risk of HIV infection among young people. According to Kenya HIV County Profiles (2016), the proportion of young men starting sex before the age of 15 in Kisii County is higher than young girls at about $60 \%$ and $21 \%$ respectively. On average, about $55 \%$ of the young people had their first sexual intercourse before the age of 15 which indicated an early sexual debut [11]. According to DHIS 2018 County report, 849 and 11514 individuals were reached with HIV prevention information on abstinence and delayed sexual debut in 2017 and 2018 respectively. There is still a need for rapid awareness campaigns and programs for youths' empowerment to delay sexual activity in them.

(iii) Stigma and Discrimination against PLHIV

Stigma and discrimination have been reported as key obstacles in the uptake of HIV services. In Kisii County, stigma and discrimination affect the ability of PLHIV and key populations namely injecting drug users (IDU), sex workers (SW) and men having sex with men (MSM) among others accessing HIV services. These categories contribute a significant proportion to new HIV infections. In a focus group discussion, a Sub-County HIV/AIDS Control Coordinator reported that fighting stigma is still difficult since Abagusii people are very conservative and private. HIV/AIDS is viewed as a death sentence in the area. She narrated how caregivers are handling orphans living with HIV Aids and she said:

"Orphaned children are isolated by care-givers. They do not share utensils or beddings with other children. The orphans are always sullen, miserable and withdrawn. For some school-going orphans, the caregivers believe that they cannot live for more than 5 years. Hence, they don't see why they should continue with schooling".
In the age group $15-49$ years, $26 \%$ of women and $46 \%$ of men expressed accepting attitudes towards people living with HIV [11]. As much as these percentages are comparable to the national averages ( $26 \%$ for women and $44 \%$ for men), there is still need for more anti-stigma campaigns in the county in order to encourage more people to know their HIV status and improve adherence to treatment among HIV-infected persons.

(iv) Gender-based violence interventions

According to the Kisii County End-Term Review Report for the Kisii HIV Strategic Plan for 2014/2015-2018/2019 in 2017, gender-based violence (GBV), though a priority indicator, it did not have any baseline data. In addition, collection of routine data has not been consistent (Table 5). It was noted that cases of GBV are best measured through surveys as a critical number of these cases do not reach the health facilities. The health system should therefore be prepared at all times to handle these cases when they get into the facilities. According to the report, the County's GBV rate was 7 cases per 10000 people in 2013/14 and 8 cases per 10 000 people in $2016 / 17$. The numbers could be higher as some cases may easily go unreported. To pay more attention to GBV clients, the GBV Unit was established at the Kisii Teaching and Referral Hospital (KTRH) at the end of 2015. According to a key informant at the Unit, 78 cases were reported in 2017 and 82 by September, 2018 with one seroconverted after three months. The number of seroconverted could be higher since majority do not pursue the cases to conclusion due to stigma. The respondent noted:

"Gender violence survivors are not keen to pursue a matter to a logical end even after being given the right information. They later withdraw and say we shall sort the matter out at home".

Table 5 is a presentation of HIV statistics in Kisii Teaching and Referral Hospital (Level 6) since 2013.

Table 5. Trends in HIV data from 2013-2017 at Kisii Teaching and Referral Hospital.

\begin{tabular}{|c|c|c|c|c|c|c|}
\hline \multirow{2}{*}{ Data element } & \multicolumn{6}{|l|}{ Data } \\
\hline & 2017 & 2016 & 2015 & 2014 & 2013 & Grand Total \\
\hline Total Tested HIV & 26779 & 49562 & 26733 & 21557 & 12209 & 136840 \\
\hline Total positive & 362 & 685 & 515 & 525 & 556 & 2643 \\
\hline Total Enrolled in Care & 256 & 378 & 324 & 383 & 467 & 1808 \\
\hline Pregnant women Starting on ART & 19 & 27 & 33 & 21 & 41 & 141 \\
\hline Total Starting on ART & 245 & 420 & 292 & 423 & 409 & 1789 \\
\hline Female above $15 y$ yrs Starting on ART & 145 & 248 & 173 & 235 & 252 & 1053 \\
\hline Female under $15 y$ rs Starting on ART & 11 & 13 & 14 & 20 & 13 & 71 \\
\hline Male under $15 y$ rs Starting on ART & 6 & 19 & 16 & 14 & 16 & 71 \\
\hline Male above $15 y$ rs Starting on ART & 82 & 138 & 87 & 153 & 124 & 584 \\
\hline Under 1yr Starting on ART & 1 & 2 & 2 & 1 & 4 & 10 \\
\hline Total Female starting ART & 156 & 261 & 187 & 255 & 265 & 1124 \\
\hline Total male starting ART & 88 & 157 & 103 & 167 & 140 & 655 \\
\hline Female above $15 y$ rs Enrolled in Care & 157 & 214 & 170 & 223 & 562 & 1326 \\
\hline Female under $15 y$ rs Enrolled in Care & 11 & 13 & 12 & 15 & 52 & 103 \\
\hline Male under $15 y r s$ Enrolled in Care & 5 & 16 & 13 & 11 & 45 & 90 \\
\hline Male above $15 y$ rs Enrolled in Care & 83 & 135 & 127 & 131 & 205 & 681 \\
\hline Under 1yr Enrolled in Care & 1 & 2 & 2 & 3 & 3 & 11 \\
\hline Total male enrolled into care & 88 & 151 & 140 & 142 & 250 & 771 \\
\hline Total Female enrolled into care & 168 & 227 & 182 & 238 & 614 & 1429 \\
\hline GSBV rape survivors seen & 78 & 82 & & & & 160 \\
\hline GSBV Rape survivors seroconverting 3 months after exposure & & 1 & & & & 1 \\
\hline
\end{tabular}

Source: DHIS 2018 
Table 5 shows that a total of 136840 people were tested for HIV at the hospital from 2013 to 2017. The number of people being tested for HIV was on an increase from the year 2013 to 2016 but dropped drastically in the year 2017. A total of 2643 people tested HIV positive from 2013 to 2017 and the number of people with HIV positive results fluctuated across the five years. An average of $0.02 \%$ people tested HIV positive in the period 2013-2017. The statistics indicate that $68.4 \%$ (1808) of the total people with HIV positive results from 2013-2017 (2 643) were enrolled in Care. The data further demonstrates that 99\% (1 789) of the people enrolled in Care started ART. Across the five years (2013-2017), there were more female who started on ART than male with a representation of $63 \%$ (1 124 of 1789 ) and 37\% (655 of 1 789) respectively. Similarly, more female (1 429) were enrolled into Care for the five years than male (771).

\subsection{Financing the HIV Response in Kisii County}

Financing towards HIV response from 2013/14 to 2015/2016 financial years increased from USD 5,191,822 to
USD 5,432,461 (Table 6). There was a slight increase in year-on-year funding for the HIV response. However, over $80 \%$ of HIV response is funded from external sources. Based on this, the researchers observed that it is necessary for harmonization of the HIV and AIDS activities and investment allocation and utilization in the County for the purposes of sustainability particularly if the international partners discontinue their aid.

In this regard, it was noted that the National AIDS Control Council (NACC) has developed the HIV Implementing Partners Online Reporting System for Implementing Partners (HIPORS) to report on all their HIV and AIDS interventions and funding. However, only $12 \%$ of the registered NGOs in Kenya have so far reported through the HIPORS [9]. This poses a challenge in coordination of the response as it does not give an accurate picture of the funding landscape in the County and in Kenya at large.

In the FY 2016/17, there were eight (8) Implementing Partners in Kisii County reporting a total of KES 478.5 Million through HIPORS system [9].

Table 6. Trends of HIV/AIDS Spending from Different Sources.

\begin{tabular}{|c|c|c|c|c|}
\hline Name of Organization & $\begin{array}{l}\text { FY 2013/14 } \\
\text { USD }\end{array}$ & $\begin{array}{l}\text { FY 2014/15 } \\
\text { (USD) }\end{array}$ & $\begin{array}{l}\text { FY 2015/16 } \\
\text { (USD) }\end{array}$ & Key Activities/Interventions \\
\hline Kisii County Government & 10310 & 56700 & 20000 & HIV workplace policy development and outreach campaigns \\
\hline CARE (K) & 4700000 & 4700000 & 4800000 & $\begin{array}{l}\text { HIV \& AIDS comprehensive care, prevention and treatment, } \\
\text { capacity building and health care systems strengthening }\end{array}$ \\
\hline International Medical Corps (IMC) & 50000 & 113005 & 287985 & $\begin{array}{l}\text { Key population, adolescents and young women target } \\
\text { programmes }\end{array}$ \\
\hline $\begin{array}{l}\text { Impact Research and Development } \\
\text { Organization (IRDO) }\end{array}$ & 92785 & 61855 & Ongoing & Key population and adolescents \\
\hline $\begin{array}{l}\text { Kenya Conference of Catholic Bishops- } \\
\text { Kenya AIDs Response Program (KCCB- } \\
\text { KARP) }\end{array}$ & 269070 & 248453 & 46100 & $\begin{array}{l}\text { Provision of high quality of HIV comprehensive care, treatment } \\
\text { and prevention services at faith-based facilitated sites }\end{array}$ \\
\hline Daraja Mbili Vision & 78000 & 54000 & 93000 & HIV \& AIDS prevention, care and support \\
\hline Mwanyagetinge Care \& Support Initiative & 41657 & 35091 & 58461 & HIV \& AIDS prevention, OVC support, care and support \\
\hline TOTAL & 5241822 & 5269104 & 5305546 & \\
\hline
\end{tabular}

Source: Kisii County HIV \& AIDs Strategic Plan 2014/15-2018/19

\section{Conclusion}

Although HIV and AIDS remains a challenge in Kisii County, commendable strides are emerging for its management and possible containment. It is assuring that many partners have come in with various forms of response to HIV and AIDS. However, there is still an urgent need for strengthening of coordination mechanisms to address duplication of roles and address the problems of inaccuracies in data for instance data on Table (2) and the prevalence given of $4.7 \%$ in the same year of 2015 Partners working in the County should share information, personnel and co-fund activities to ensure efficiency in HIV and AIDS response. The County Government should work towards gradually increasing HIV and AIDS financing with a view to taking over if and when partners pull out.

\section{Conflict of Interest}

There is no conflict of interest

\section{Acknowledgements}

The authors are grateful to National Research Fund-Kenya (NRF) for financial assistance under grant number $\mathrm{NRF} / 1 / \mathrm{MMC} / 308$. We also thank respondents for availing necessary documents and data for this paper.

\section{References}

[1] KNBS [Kenya] Kenya Demographic and Health Survey 2008-09 Preliminary Report. Calverton, Maryland. KNBS, NACC, NASCOP, NPHLS, KEMRI, NCAPD, ICF Macro, September 2009.

[2] Kisii County HIV \& AIDs Strategic Plan 2014/15-2018/19. Kisii County, Kisii.

[3] UNAIDS DATA. Geneva: UNAIDS. 2017.

[4] NACC. Kenya AIDS Response Progress Report. 2014; Nairobi: NACC.Nairobi: $\mathrm{MoH}$. 
[5] NACC. Kenya HIV Prevention Revolution Road Map. 2014; Nairobi: $\mathrm{MoH}$.

[6] NACC. Kenya HIV Estimates 2015; MoH, Nairobi Kenya.

[7] NACC. Kenya HIV Estimates 2018. 2018; MoH, Nairobi Kenya.

[8] Creswell, J. Research Design: Qualitative, Quantitative, and Mixed Methods Approaches. $2^{\text {nd }}$ Ed. University of Nebraska, Lincoln: Sage Publications. 2003.

[9] NACC Report On the HIV Implementing Partners Online Reporting System (HIPORS) for The Financial Year 2016/2017 2018. 2018;. NACC, Nairobi Kenya.
[10] KNBS Kenya Demographic and Health Survey. 2014; Nairobi: Kenya.

[11] NACC. Kenya HIV County Profiles. 2016; Nairobi: NACC. Kisii County.

[12] Ministry of Education, Science And Technology (2004). Education Sector Policy on HIV and AIDS. 2004; MoE Kenya.

[13] Ministry of Education, Science And Technology. Education Sector Policy On HIV AND AIDS, Second edition. 2013; MoE Kenya.

[14] NACC. Kenya Fast Track Plan to End HIV and AIDS among adolescents and young people. 2015; NACC, Nairobi Kenya. 